\title{
Improved Rotor Position Estimation in Extended Back-EMF Based Sensorless PM Brushless AC Drives with Magnetic Saliency
}

\author{
Y. Li, Z. Q. Zhu, D. Howe, and C. M. Bingham \\ Department of Electronic and Electrical Engineering, University of Sheffield, \\ Mappin Street, Sheffield S1 3JD, UK
}

\begin{abstract}
An improved extended back-EMF based sensorless control method is proposed for a brushless AC motor equipped with an interior permanent magnet rotor. It accounts for $d q$-axis cross-coupling magnetic saturation by introducing an apparent mutual winding inductance. The error which results in the estimated rotor position when the influence of cross-coupling magnetic saturation is neglected is analyzed analytically, predicted by finite element analysis, and confirmed experimentally, for various $d$ - and $q$-axis currents. It is shown that a significant improvement in the accuracy of the rotor position estimation can be achieved by the proposed method, as confirmed by measurements.
\end{abstract}

\section{INTRODUCTION}

It is desirable to eliminate the need for a precision rotor position sensor in permanent magnet (PM) brushless $\mathrm{AC}$ (BLAC) drives, by employing a sensorless technique. While signal injection based sensorless schemes can successfully estimate the rotor position at standstill and low speeds [1], back-EMF based sensorless techniques are only applicable to higher speeds [2]-[4]. Hence, it is common to employ a hybrid sensorless technique, which uses both a signal injection based method and a back-EMF based method [5]. Back-EMF based sensorless methods were first developed to estimate the rotor position of BLAC motors having a surface-mounted PM rotor without rotor magnetic saliency. They were then extended to BLAC motors having different $\mathrm{d}$-axis and $\mathrm{q}$-axis inductances [2]-[4], which led to the 'extended' back-EMF method in which the $d$-axis inductance term was combined with the EMF term in order to make the impedance matrix of the $d q$-axis voltage equations symmetrical. In [2], the influence of magnetic saturation was neglected, and the q-axis apparent inductance was assumed to be constant. Magnetic saturation was subsequently considered in [3] [4]. However, although the influence of dq-axis cross-coupling magnetic saturation is well-known in permanent magnet brushless machines [6], for simplicity it has not been considered in existing extended back-EMF based sensorless schemes [2]-[5]. The modeling of dq-axis cross-coupling magnetic saturation, the investigation of its influence on the accuracy of the rotor position estimation in the extended back-EMF based sensorless control method, and the development of a method for improving the accuracy of the estimated rotor position are the subject of this paper.

A BLAC motor model which accounts for dq-axis cross-coupling magnetic saturation and the improved extended back-EMF based sensorless control method are presented in section II. In section III, the errors in the estimated rotor position which result when the influence of dq-axis cross-coupling magnetic saturation is neglected is analyzed analytically and predicted by finite element analysis for various $d$ - and $q$-axis currents. Finally, the performance of the proposed improved extended back-EMF based sensorless control method is demonstrated experimentally in section IV.

\section{Modeling of BLAC Motor Accounting For DQ-Axis Cross-Coupling MAGNetic SATURATION AND IMPROVED EXTENDED BACK-EMF BASED SENSORLESS METHOD}

The 3-phase voltages of a BLAC motor are given by:

$$
\left[\begin{array}{l}
v_{a} \\
v_{b} \\
v_{c}
\end{array}\right]=\left[\begin{array}{ccc}
R_{s} & 0 & 0 \\
0 & R_{s} & 0 \\
0 & 0 & R_{s}
\end{array}\right]\left[\begin{array}{l}
i_{a} \\
i_{b} \\
i_{c}
\end{array}\right]+\left[\begin{array}{l}
d \psi_{a} / d t \\
d \psi_{b} / d t \\
d \psi_{c} / d t
\end{array}\right]
$$

where $v_{a}, v_{b}, v_{c}, i_{a}, i_{b}, i_{c}, \psi_{a}, \psi_{b}$ and $\psi_{c}$ are the 3 -phase voltages, currents, and flux-linkages, respectively, and $R_{s}$ is the phase resistance. (1) can be transformed into the rotor reference frame as:

$$
\left[\begin{array}{l}
v_{d} \\
v_{q}
\end{array}\right]=\left[\begin{array}{cc}
R_{s} & 0 \\
0 & R_{s}
\end{array}\right]\left[\begin{array}{l}
i_{d} \\
i_{q}
\end{array}\right]+\left[\begin{array}{l}
d \psi_{d} / d t-\omega_{r} \psi_{q} \\
d \psi_{q} / d t+\omega_{r} \psi_{d}
\end{array}\right]
$$

where $v_{d}, v_{q}, i_{d}, i_{q}, \psi_{d}$, and $\psi_{q}$ are the $d$ - and $q$-axis voltages, currents, and flux-linkages, respectively, and $\omega_{r}$ is the rotor electrical angular velocity. Fig. 1 shows the predicted $d$ - and $q$-axis flux-linkages of a BLAC motor which has an interior PM rotor, as calculated by finite element analysis, for various $d$ - and $q$-axis currents.

Clearly, $\psi_{d}, \psi_{q}, d \psi_{d} / d t$ and $d \psi_{q} / d t$ vary non-linearly with the $d$ - and $q$-axis currents, due to the influence of magnetic saturation. They can be written as [5]: 
$\left\{\begin{array}{l}\psi_{d}=L_{d} i_{d}+L_{d q} i_{q}+\psi_{m} \\ \psi_{q}=L_{q} i_{q}+L_{q d} i_{d}\end{array}\right.$

$$
\left\{\begin{array}{l}
\frac{d \psi_{d}}{d t}=\frac{\partial \psi_{d}}{\partial i_{d}} \frac{d i_{d}}{d t}+\frac{\partial \psi_{d}}{\partial i_{q}} \frac{d i_{q}}{d t}=L_{d h} \cdot p i_{d}+L_{d q h} \cdot p i_{q} \\
\frac{d \psi_{q}}{d t}=\frac{\partial \psi_{q}}{\partial i_{q}} \frac{d i_{q}}{d t}+\frac{\partial \psi_{q}}{\partial i_{d}} \frac{d i_{d}}{d t}=L_{q h} \cdot p i_{q}+L_{q d h} \cdot p i_{d}
\end{array}\right.
$$

where $L_{d}, L_{q}, L_{d q}$ and $L_{q d}$, are the $d$ - and $q$-axis apparent self- and mutual-inductances, $L_{d h}, L_{q h}, L_{d q h}$, and $L_{q d h}$ are the $d$ - and $q$-axis incremental self- and mutual-inductances, respectively, and $p=d / d t$.

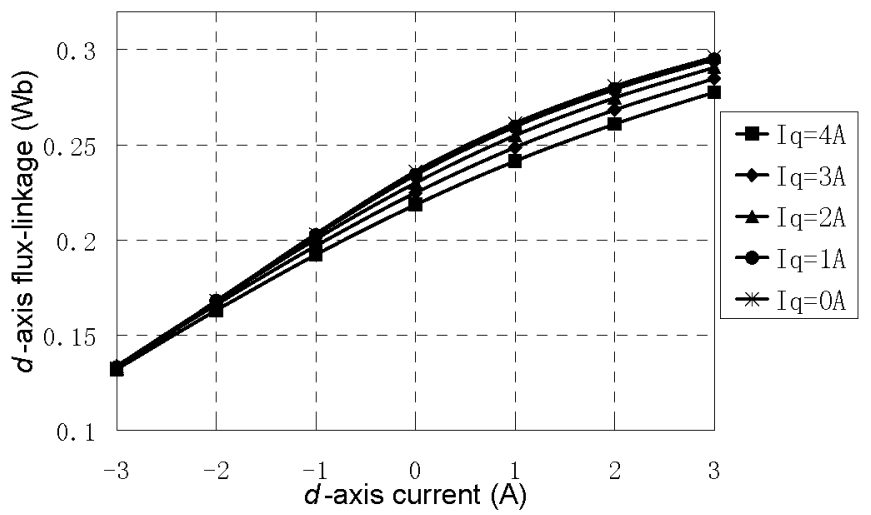

(a) $d$-axis flux-linkage, $\psi_{d}$.

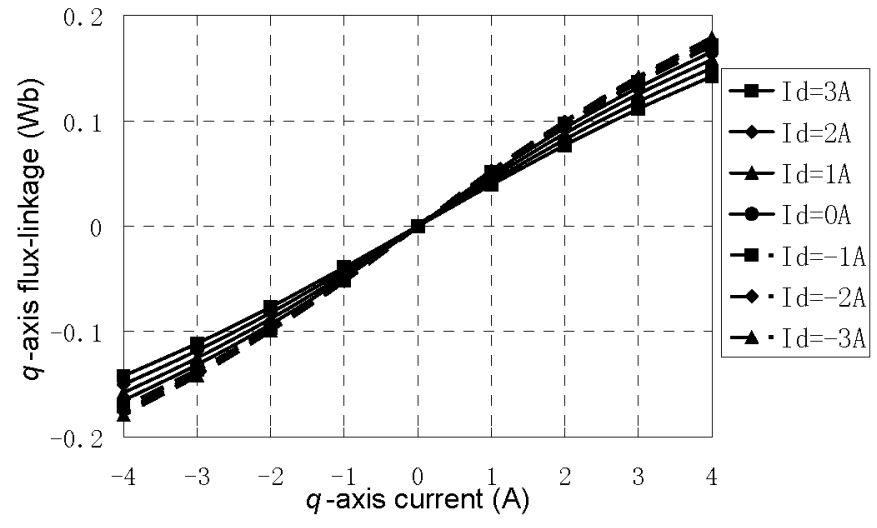

(b) $q$-axis flux-linkage, $\psi_{q}$.

Fig. 1. Finite element predicted $d$ - and $q$-axis flux-linkages for various $d$ - and $q$-axis currents.

Equations (3) and (4) can be substituted into (2), and the $d q$-axis voltage equation re-written as:

$$
\begin{aligned}
{\left[\begin{array}{c}
v_{d} \\
v_{q}
\end{array}\right] } & {\left[\begin{array}{cc}
R_{s}+L_{d h} p-\omega_{r} L_{q d} & -\omega_{r} L_{q}+L_{d q h} p \\
\omega_{r} L_{d}+L_{q d h} p & R_{s}+L_{q h} p+\omega_{r} L_{d q}
\end{array}\right]\left[\begin{array}{c}
i_{d} \\
i_{q}
\end{array}\right]+\left[\begin{array}{c}
0 \\
\omega_{r} \psi_{m}
\end{array}\right] } \\
& =\left[\begin{array}{cc}
R_{s}+L_{d h} p-\omega_{r} L_{q d} & -\omega_{r} L_{q}+L_{d q h} p \\
\omega_{r} L_{q}-L_{d q h} p & R_{s}+L_{d h} p-\omega_{r} L_{q d}
\end{array}\right]\left[\begin{array}{c}
i_{d} \\
i_{q}
\end{array}\right]+\left[\begin{array}{c}
0 \\
E_{e x}
\end{array}\right]
\end{aligned}
$$

where $E_{e x}$ is the extended back-EMF, viz:

$$
\begin{aligned}
E_{e x}= & \omega_{r} \psi_{m}+\left(\omega_{r} L_{d}-\omega_{r} L_{q}+L_{q d} p+L_{d q} p\right) i_{d} \\
& +\left(L_{q} p-L_{d} p+\omega_{r} L_{d q}+\omega_{r} L_{q d}\right) i_{q}
\end{aligned}
$$

As the actual rotor position, $\theta_{r}$, is not available in a sensorless scheme, (5) is required to be transformed into the estimated $d q$-axis reference frame, $\theta_{r}^{e}$, i.e.

$\left[\begin{array}{l}v_{d}^{e} \\ v_{q}^{e}\end{array}\right]=\mathrm{T}\left[\begin{array}{l}v_{d} \\ v_{q}\end{array}\right]$

$=\mathrm{T}\left[\begin{array}{cc}R_{s}+L_{d h} p-\omega_{r} L_{q d} & -\omega_{r} L_{q}+L_{d q h} p \\ \omega_{r} L_{q}-L_{d q h} p & R_{s}+L_{d h} p-\omega_{r} L_{q d}\end{array}\right] \mathrm{T}^{-1} \cdot \mathrm{T}\left[\begin{array}{c}i_{d} \\ i_{q}\end{array}\right]+\mathrm{T}\left[\begin{array}{c}0 \\ E_{e x}\end{array}\right]$
$=\left[\begin{array}{cc}R_{s}+L_{d h} p-\omega_{r} L_{q d} & -\omega_{r} L_{q}+L_{d q h} p \\ \omega_{r} L_{q}-L_{d q h} p & R_{s}+L_{d h} p-\omega_{r} L_{q d}\end{array}\right]\left[\begin{array}{c}i_{d}^{e} \\ i_{q}^{e}\end{array}\right]+\left[\begin{array}{c}E_{e x \_d} \\ E_{e x \_q}\end{array}\right]$

where $v_{d}^{e}, v_{q}^{e}, i_{d}^{e}, i_{q}^{e}, E_{e x_{-} d}$ and $E_{e x_{-} q}$ are the $d$ - and $q$-axis voltages, currents, and extended back-EMFs in the estimated rotor reference frame, and $\mathbf{T}$ is the rotation matrix, which is given by

$$
\begin{aligned}
& \mathrm{T}=\left[\begin{array}{cc}
\cos (\Delta \theta) & \sin (\Delta \theta) \\
-\sin (\Delta \theta) & \cos (\Delta \theta)
\end{array}\right] \\
& E_{\text {ex_d }}=E_{e x} \sin \Delta \theta \\
& E_{e x \_q}=E_{e x} \cos \Delta \theta
\end{aligned}
$$

where $\Delta \theta=\theta_{r}^{e}-\theta_{r}$ is the error in the estimated rotor position. As shown in (8), the error can be calculated from $E_{e x_{-} d}$, and $E_{e x_{-} q}$, where:

$$
\begin{aligned}
& \left\{\begin{array}{l}
E_{e x_{-} d}=v_{d}^{e}-\left(R_{s}+L_{d h} p-\omega_{r} L_{q d}\right) i_{d}^{e}+\left(\omega_{r} L_{q}-L_{d q h} p\right) i_{q}^{e} \\
E_{e x_{-} q}=v_{q}^{e}-\left(R_{s}+L_{d h} p-\omega_{r} L_{q d}\right) i_{q}^{e}-\left(\omega_{r} L_{q}-L_{d q h} p\right) i_{d}^{e}
\end{array}\right. \\
& \Delta \theta=\arctan \left(E_{e x \_d} / E_{e x \_q}\right) \approx E_{e{ }_{-} d} / E_{e x \_q}
\end{aligned}
$$

In the steady-state and during slowly changing operational conditions, the derivatives of the $d$ - and $q$-axis currents are sufficiently small, i.e., $p i_{d}{ }^{e} \approx 0, p i_{q}{ }^{e} \approx 0$, that the relevant terms in (9) can be neglected. Therefore, (9) becomes:

$$
\left\{\begin{array}{l}
E_{e x_{-} d}=v_{d}^{e}-R_{s} i_{d}^{e}+\omega_{r}\left(L_{q} i_{q}^{e}+L_{q d} i_{d}^{e}\right) \\
E_{e x_{-} q}=v_{q}^{e}-R_{s} i_{q}^{e}-\omega_{r}\left(L_{q} i_{d}^{e}-L_{q d} i_{q}^{e}\right)
\end{array}\right.
$$

$\Delta \theta=\arctan \left(E_{e x \_d} / E_{e x q q}\right) \approx E_{e x \_d} / E_{e x q}$

The estimated rotor position error, $\Delta \theta$, which is calculated from (10), can then be used to correct the estimated rotor position, $\theta_{r}{ }_{r}$, and speed, $\omega_{r}^{e}$. Clearly, when $E_{e x d}$ is forced to zero in the extended back-EMF sensorless control scheme, the estimated rotor position is equal to the actual rotor position, i.e. $\Delta \theta=0$.

\section{ANALYSIS OF Estimated Rotor POSITION ERROR IN EXTENDED BACK-EMF BASED SENSORLESS METHOD}

In theory, in the extended back-EMF based sensorless control 
scheme, the error in the estimated rotor position will be zero if accurate values for all the parameters in (10) are used. However, the accuracy of the parameters $L_{q}$ and $L_{q d}$ is influenced significantly by the $d$-and $q$-axis currents which cause the level of magnetic saturation to vary. $L_{q}$ and $L_{q d}$ can be calculated from the $d$ - and $q$-axis flux-linkages:

$$
\begin{aligned}
& L_{d}\left(i_{d}\right)=\psi_{d}\left(i_{d}, 0\right) / i_{d} \\
& L_{q}\left(i_{q}\right)=\psi_{q}\left(0, i_{q}\right) / i_{q} \\
& L_{d q}\left(i_{d}, i_{q}\right)=\left[\psi_{d}\left(i_{d}, i_{q}\right)-\psi_{d}\left(i_{d}, 0\right)\right] / i_{q} \\
& L_{q d}\left(i_{d}, i_{q}\right)=\left[\psi_{q}\left(i_{d}, i_{q}\right)-\psi_{q}\left(0, i_{q}\right)\right] / i_{d}
\end{aligned}
$$

The finite element predicted variation of $L_{d}, L_{q}, L_{d q}$ and $L_{q d}$, for the motor under consideration, are shown in Fig. 2.

Since $L_{d}$ and $L_{d q}$ are not used in the conventional extended back-EMF based sensorless scheme, (10), their prediction accuracy will not affect the accuracy of the estimated rotor position. The apparent self- and mutual-inductances in (10), $L_{q}$, and $L_{q d}$, are used to predict the $q$-axis flux-linkage, $\psi_{q}=L_{q} i_{q}{ }^{e}+L_{q d} d_{d}{ }^{e}$. In [2], $L_{q d}$ is neglected and the constant apparent self-inductance $L_{q}$ at $i_{d}=0$ and $i_{q}=i_{q N}$ is used, i.e.:

$L_{q}=L_{q}\left(0, i_{q N}\right)=\psi_{q}\left(0, i_{q N}\right) / i_{q N}$

where $i_{q N}$ is the rated $q$-axis current.

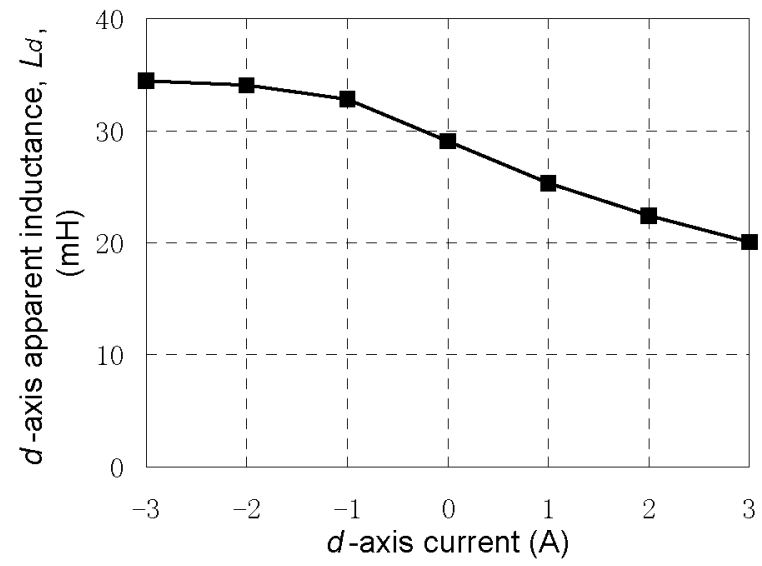

(a) $L_{d}$

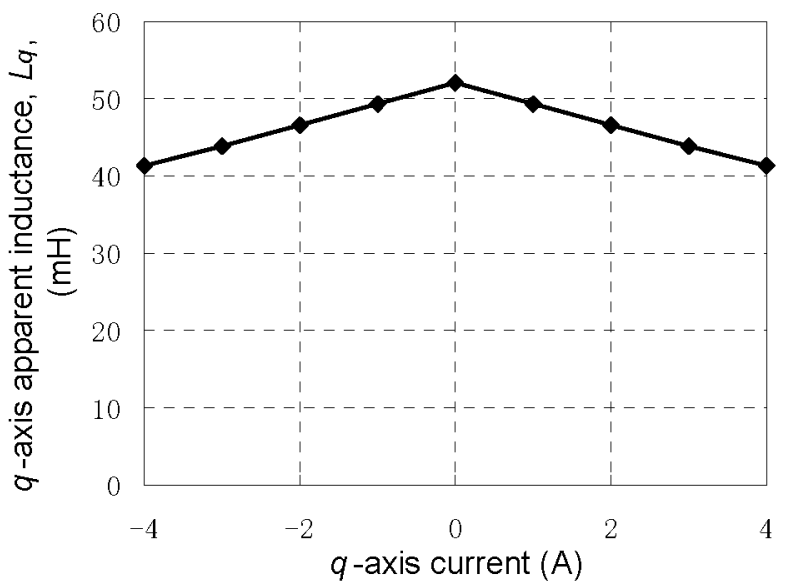

(b) $L_{q}$

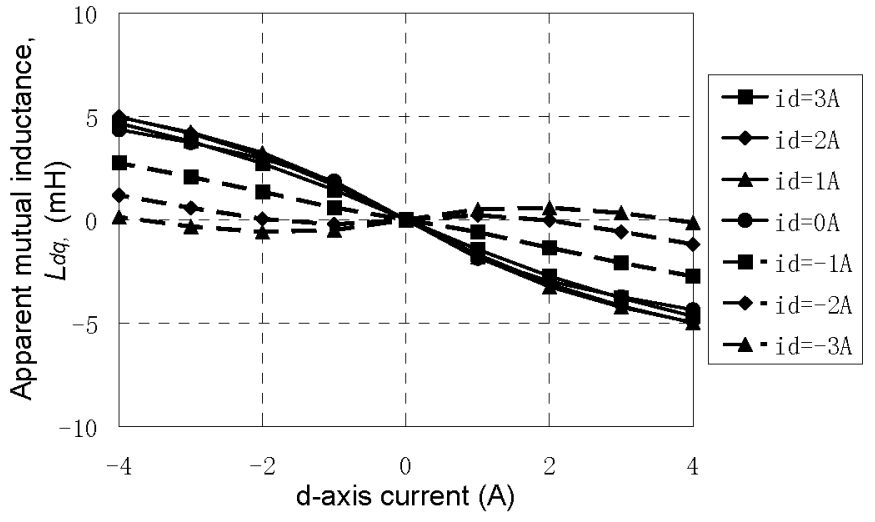

(c) $L_{d q}$

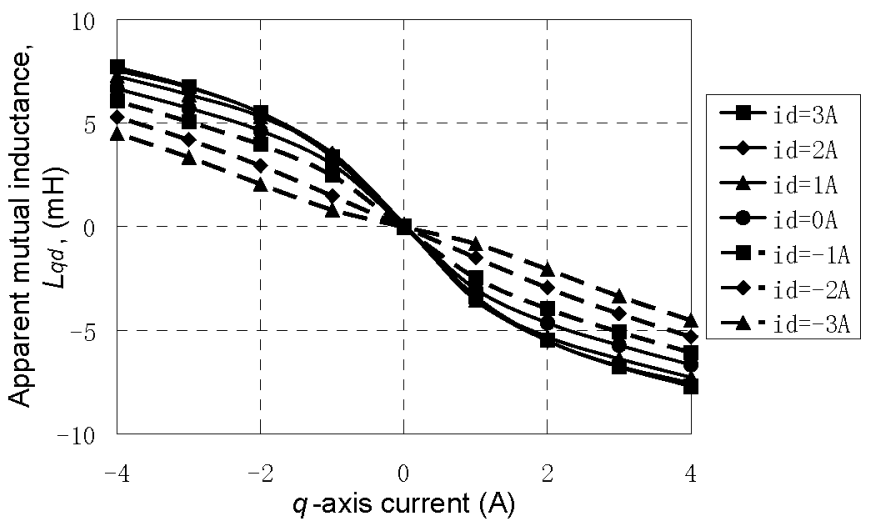

(d) $L_{q d}$

Fig. 2. Finite element predicted apparent self- and mutual- inductances, $L_{d,} L_{q}$, $L_{d q}$ and $L_{q d .}$

In the conventional extended back-EMF method [2], the $d$-axis extended back-EMF in the estimated rotor reference frame is calculated and controlled to be zero, i.e.

$v_{d}^{e}-R_{s} i_{d}^{e}+\omega_{r} L_{q}\left(0, i_{q N}\right) i_{q}^{e}=0$

As shown in (12), since the influence of magnetic saturation on the $q$-axis and dq-axis cross-coupling are neglected, an error in the rotor position estimation will be introduced in the conventional extended back-EMF based sensorless scheme. Equation (13) can then be substituted into (10) to predict the error in the estimated rotor position using the method proposed in [2], viz.:

$$
\Delta \theta=\left\{\left[L_{q}\left(0, i_{q}\right)-L_{q}\left(0, i_{q N}\right)\right] i_{q}^{e}+L_{q d} i_{d}^{e}\right\} /\left(E_{e x \_q} / \omega_{r}\right)
$$

When the effect of magnetic saturation on the $q$-axis, and its variation with the $q$-axis current is considered, the apparent self- inductance, $L_{q}$, in (10) is given by [3][4]:

$L_{q}=L_{q}\left(0, i_{q}\right)=\psi_{q}\left(0, i_{q}\right) / i_{q}$

In [3][4], the $d$-axis extended back-EMF in the estimated rotor position reference frame is calculated and controlled to be zero, i.e.:

$v_{d}^{e}-R_{s} i_{d}^{e}+\omega_{r} L_{q} i_{q}^{e}=0$ 
However, the effect of $d q$-axis cross-coupling was neglected in [3] and [4]. Thus, equation (16) can be substituted into (10) to obtain the error in estimated rotor position using the method proposed in [3] and [4], viz.:

$\Delta \theta=L_{q d} i_{d}^{e} /\left(E_{e x_{-} q} / \omega_{r}\right)$

Therefore, when the conventional extended back-EMF based sensorless control schemes which were described in [2] [3] and [4], in which the influence of dq-axis cross-coupling magnetic saturation was neglected, are employed, the error in the estimated rotor position can be predicted from either (14), when $L_{q}$ is assumed to be constant, i.e. $L_{q}=L_{q}\left(0, i_{q N}\right)$, or from (17) when $L_{q}$ varies with saturation, i.e. $L_{q}=L_{q}\left(0, i_{q}\right)$, using the finite element predicted winding inductances which were shown in Fig.2. The predicted variation of the rotor position error for each scenario for the motor under consideration is shown in Figs. 3(a) and (b), respectively. As will be seen, the larger the $d$ and $q$-axis currents, the larger the error in the estimated rotor position. In addition, it will also be noted that, for this particular motor, the accuracy of the estimated rotor position is not improved by accounting for the influence of the variation in magnetic saturation on the $q$-axis with the $q$-axis current.

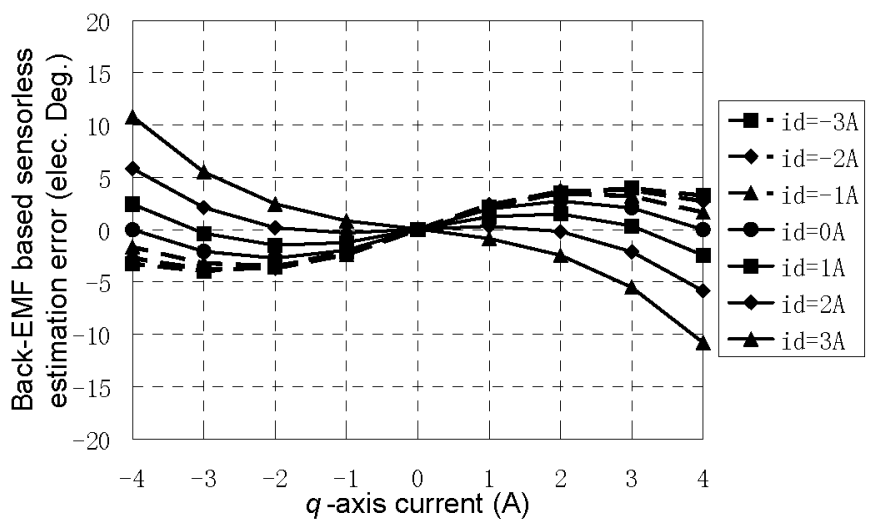

(a) $L_{q}=L_{q}\left(0, i_{q N}\right), L_{q d}=0 \mathrm{mH}, \operatorname{RMS}\left(\theta_{r}{ }^{e}-\theta_{r}\right)=3.1^{\circ}$

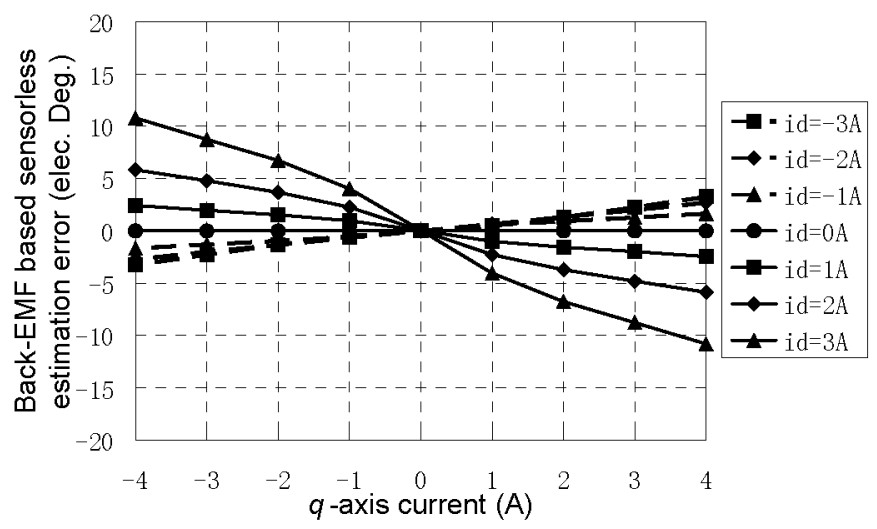

(b) $L_{q}=L_{q}\left(0, i_{q}\right), L_{q d}=0 \mathrm{mH}, \operatorname{RMS}\left(\theta_{r}{ }^{e}-\theta_{r}\right)=3.3^{\circ}$.

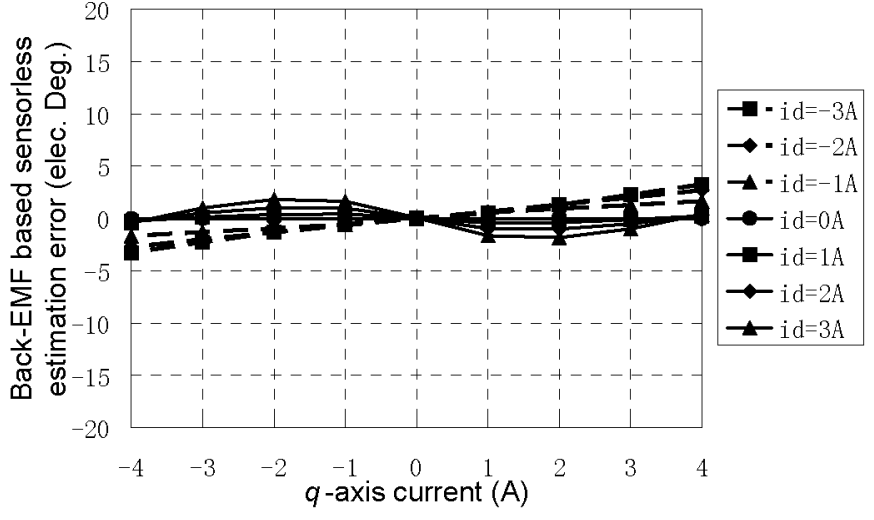

(c) $L_{q}=L_{q}\left(0, i_{q}\right), L_{q d}=L_{q d s}, \operatorname{RMS}\left(\theta_{r}{ }^{e}-\theta_{r}\right)=1.2^{\circ}$

Fig. 3. Variation of predicted error in estimated rotor position with various $d$ and $q$-axis currents, for conventional and proposed extended back-EMF based sensorless schemes.

Since the variation of $L_{q d}$ with $i_{d}$ and $i_{q}$ is a complex function which is difficult to implement on a DSP, a much simpler approach is proposed in which an approximation function, $L_{q d s}$, is used to represent the variation of $L_{q d}$ with $i_{d}$ and $i_{q}$, viz.

$L_{q d s}= \begin{cases}0, & i_{d}^{e} \leq 0 \\ -0.002 i_{q}^{e}, & i_{d}^{e}>0\end{cases}$

for the motor which is being considered.

The $d$-axis extended back-EMF in the estimated rotor reference frame is then calculated and controlled to be zero as:

$v_{d}^{e}-R_{s} i_{d}^{e}+\omega_{r}\left(L_{q}^{i} i_{q}^{e}+L_{q d s} i_{d}^{e}\right)=0$

Equation (19) is then substituted into (10) to obtain the error in the estimated rotor position when the cross-coupling, $L_{q d}$, is approximated by $L_{q d s}$, i.e.:

$\Delta \theta=\left(L_{q d}-L_{q d s}\right) i_{d}^{e} /\left(E_{e x \underline{q}} / \omega_{r}\right)$

The predicted variation in the error in the estimated rotor position is now reduced significantly, as shown in Fig. 3(c).

\section{EXPERIMENTAL RESULTS}

The error in the estimated rotor position, which results when the conventional and proposed extended back-EMF sensorless schemes are employed, has been measured experimentally, with reference to the actual rotor position as measured by a 1024 pulse-per-revolution encoder. As stated earlier, the BLAC motor has an interior PM rotor, its parameters being given in Table I. The sensorless controller is implemented on a TMS320C31 DSP, the frequency of the AD sampling rate, the control loop, and the PWM switching all being $5 \mathrm{kHz}$. The error in the estimated rotor position was measured for various $d$ - and $q$-axis currents. With the conventional extended back-EMF based sensorless scheme, in which the $q$-axis apparent inductance, $L_{q}$, is assumed to be constant and the influence of $d q$-axis cross-coupling effect is neglected, the rotor position 
estimation error is large, Fig. 5 (a), e.g. $16 \cdot 6^{\circ}$ at $i_{d}=3 \mathrm{~A}, i_{q}=4 \mathrm{~A}$, the root mean square (RMS) error being $4.3^{\circ}$. As will be seen by comparing Figs. 5(a) and (b), when the influence of magnetic saturation on $L_{q}$ is considered in the conventional extended back-EMF based sensorless scheme, there is little, if any, improvement in the accuracy of the rotor position estimation accuracy, e.g. $15.5^{\circ}$ at $i_{d}=3 \mathrm{~A}, i_{q}=4 \mathrm{~A}$, with the root mean square (RMS) error being $4.4^{\circ}$. This is consistent with the earlier predictions.

The cross-coupling between the $d$ - and $q$-axes due to magnetic saturation can be accounted for directly in the extended back-EMF sensorless scheme by using (18) in (10), i.e. (19). In this case, the RMS error in the estimated rotor position is reduced significantly, to $\sim 2.0^{\circ}$, Fig. 5(c), the small error being due to the inaccuracy of the finite element predicted apparent inductances and also the approximation in (18).

Alternatively, the error in the estimated rotor position due to the neglect of the dq-axis cross-coupling effect can also be compensated for indirectly, by firstly assuming $L_{q d}$ to be zero and then compensating for the resulting rotor position error according to the measured error, Fig. 5(b), which, for simplicity, is approximated by (21).

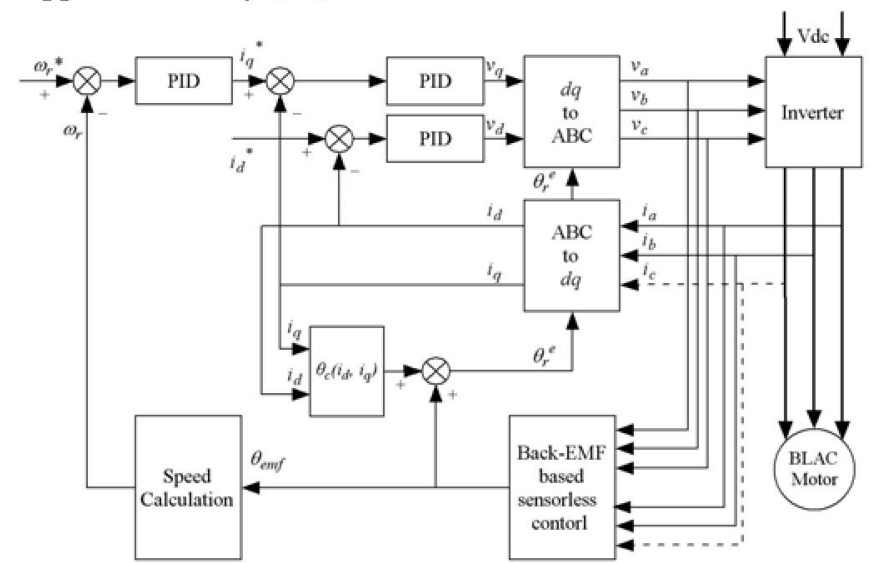

Fig. 4. Extended back-EMF based sensorless scheme with compensation for rotor position error due to cross-coupling.

$\theta_{c}= \begin{cases}0, & i_{d} \leq 0 \\ K_{r} i_{d} i_{q}, & i_{d}>0\end{cases}$

where $\theta_{c}$ is the value of the rotor position compensation and $K_{r}$ is the compensation factor. For the BLAC motor under consideration, $K_{r}$ is approximated from Fig. $5(\mathrm{~b})$ as $K_{r}=0.9^{\%} / \mathrm{A}^{2}$. The corresponding error compensation scheme is shown in Fig.4. In this case, information regarding $L_{q d}$ is not required, since the error which is to be compensated for, i.e. Fig.5(b), is measured directly in advance. When such a compensation scheme is employed, the RMS error in the estimated rotor position is reduced to $2.2^{\circ}$, as shown in Fig. 5(d).

The foregoing analyses clearly indicate the significance of dq-axis cross-coupling magnetic saturation on the accuracy of in the extended back-EMF sensorless scheme, and validates the proposed improvement.
TABLE I PARAMETERS OF BLAC MOTOR

\begin{tabular}{|l|l|}
\hline Rated voltage (peak) & $158 \mathrm{~V}$ \\
\hline Rated current (peak) & $4.0 \mathrm{~A}$ \\
\hline Rated power & $0.6 \mathrm{~kW}$ \\
\hline Rated speed $\left(n_{N}\right)$ & $1000 \mathrm{rpm}$ \\
\hline Rated torque & $4.0 \mathrm{Nm}$ \\
\hline Pole number $(2 p)$ & 6 \\
\hline Stator winding resistance $\left(R_{S}\right)$ & $6.0 \Omega$ \\
\hline
\end{tabular}

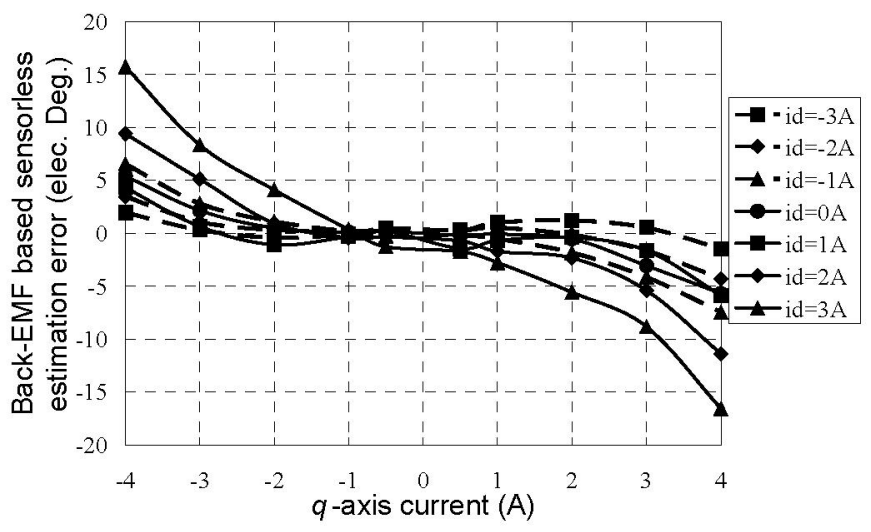

(a) $L_{q}=43 \mathrm{mH}, L_{q d}=0 \mathrm{mH}, \operatorname{RMS}\left(\theta_{r}{ }^{e}-\theta_{r}\right)=4.3^{\circ}$

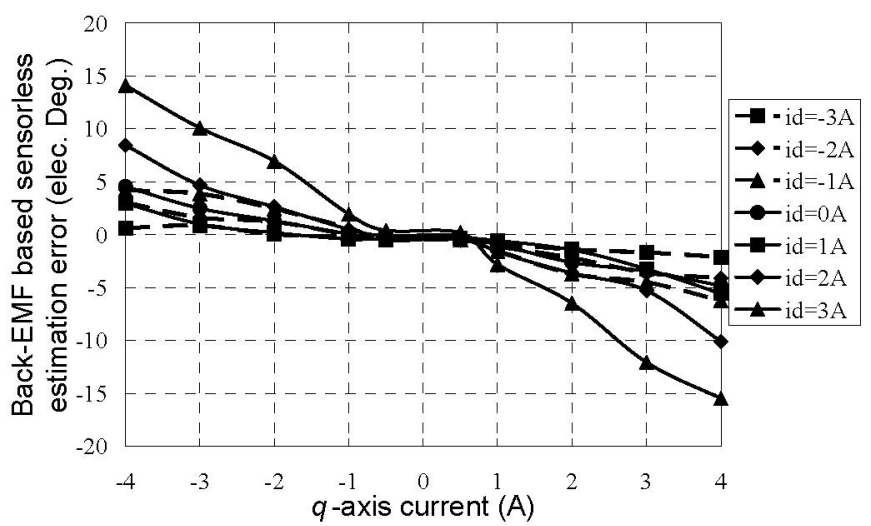

(b) $L_{q}=51-2\left|i_{q}^{e}\right| \mathrm{mH}, L_{q d}=0 \mathrm{mH}, \operatorname{RMS}\left(\theta_{r}^{e}-\theta_{r}\right)=4.4^{\circ}$

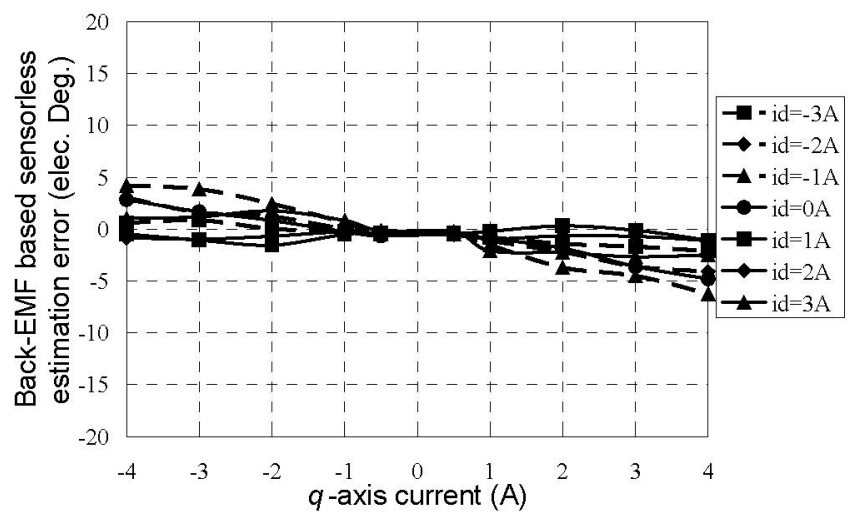

(c) $L_{q}=51-2\left|{ }_{i q}^{e}\right| \mathrm{mH}, L_{q d}$ is approximated by (18), i.e. $L_{q d}=0 \mathrm{mH}$ when $i_{d}<0 \mathrm{~A}$, $L_{q d}=-2 i_{q}^{e} \mathrm{mH}$ when $i_{d} \geq 0 \mathrm{~A}, \operatorname{RMS}\left(\theta_{r}{ }^{e}-\theta_{r}\right)=2.0^{\circ}$ 


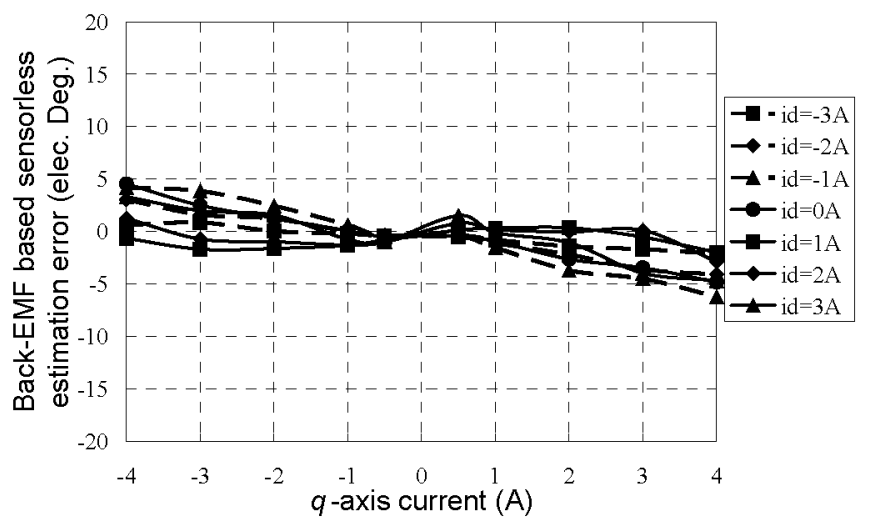

(d) $L_{q}=51-2||_{q}^{e} \mid \mathrm{mH}, L_{q d}=0 \mathrm{mH}$ and error is compensated for by (21), $\operatorname{RMS}\left(\theta_{r}{ }^{e}-\theta_{r}\right)=2.2^{\circ}$

Fig. 5. Variation of measured error in estimated rotor position with $d$-and $q$-axis currents.

\section{CONCLUSIONS}

The conventional extended back-EMF based sensorless control method has been improved by accounting for cross-coupling between the $\mathrm{d}$ - and $\mathrm{q}$-axes and magnetic saturation by introducing an apparent mutual winding inductance for a permanent magnet brushless $\mathrm{AC}$ motor with magnetic saliency. The error in the estimated rotor position which arises when cross-coupling and magnetic saturation are neglected has been analyzed analytically, predicted by finite element analysis, and confirmed by measurements, for various $d$ - and $q$ - axis currents. Measurements confirm that a significant improvement in the accuracy of the estimated rotor position estimation can be achieved by using the proposed extended back-EMF based sensorless technique.

\section{REFERENCES}

[1] J.H. Jang, S.K. Sul, J.I. Ha, K. Ide, and M. Sawamura, "Sensorless drive of surface-mounted permanent-magnet motor by high-frequency signal injection based on magnetic saliency," IEEE Trans. Industry Applications, vol. 39, no. 4, pp. 1031-1039, 2003.

[2] Z. Chen, M. Tomita, S. Koki, and S. Okuma, "An extended electromotive force model for sensorless control of interior permanent-magnet synchronous motors," IEEE Trans. Industrial Electronics, vol.50, no.2, pp 288-295, 2003

[3] S. Morimoto, K. Kawamoto, M. Sanada, and Y. Takeda, "Sensorless control strategy for salient-pole PMSM based on extended EMF in rotating reference frame," IEEE Trans. Industry Applications, vol.38, no.4, pp. 1054-1061, 2002.

[4] H. Kim, M. C. Harke, and R. D. Lorenz, "Sensorless control of interior permanent-magnet machine drives with zero-phase lag position estimation," IEEE Trans. Industry Applications, vol.39, no.6, pp. 1726-1733, 2003.

[5] T. Aihara, A. Toba, T. Yanase, A. Mashimo, and K. Endo, "Sensorless torque control of salient-pole synchronous motor at zero-speed operation," IEEE Trans. Power Electronics, vol. 14, no. 1, pp. 202-208, 1999.

[6] B. Stumberger, G. Stumberger, D. Dolinar, A. Hamler, and M. Trlep, "Envaluation of saturation and cross-magnetization effects in interior permanent-magnet synchronous motor," IEEE Trans. Industry Applications, vol. 39, no. 5, pp. 1264-1271, 2003. 